\title{
A Method of Controlling the Rate of Air Movement in Transpiration Experiments.
}

\author{
BY \\ V. H. BLACKMAN \\ AND \\ R. C. KNIGHT, \\ From the Department of Plant Physiology and Pathology, Imperial College of Science \\ and Technology, London.
}

\section{With one Figure in the Text.}

THE influence of air movements on the rate of transpiration of plants I has long been recognized but attempts to control this factor during experiments on transpiration have been very few. Investigators have usually contented themselves with periodical observations of the speed of the air in the vicinity of the plant, or else have attempted to eliminate from their results the effects of air-currents and other external factors by directing their attention, not to absolute transpiration, but to 'relative transpiration', i. e. to the ratio between the rate of transpiration from the plant and the rate of evaporation from an atmometer. Such a method is, however, not altogether satisfactory since the response of the plant and that of the atmometer to air-currents are not proportional, as has been demonstrated elsewhere. ${ }^{1}$

On the other hand, attempts to obviate the effects of air-currents by investigations of transpiration in 'still air' are equally unsatisfactory, on account of the difficulty of ensuring that the air is really still. Experience has shown that in spite of precautions that may be taken the air of a laboratory is in constant slight motion, and such chance air-currents will influence the 'shells' of water vapour over the evaporating surfaces and consequently the rate of transpiration will continually vary.

In critical work on transpiration it would therefore seem advisable that work should be carried out neither in 'still air', nor in the open where the wind currents may vary with great rapidity, but under conditions of constant air movement which can be regulated at will.

1 R. C. Knight, in a paper appearing later in Vol. XXXI.

[Annals of Botany, Vol. XXXI. No. CXXII. April, 1917.] 


\section{Blackman and Knight.-A Method of Controlling the}

Giddings ${ }^{1}$ controlled the conditions of air movements in some transpiration experiments by exposing his plants to the wind produced by a fan attached to an electric motor, but he observes that the plants farthest from the fan were probably subjected to chance air-currents also; no steps were taken to remedy this.

The present writers in some unpublished experiments on transpiration attempted a more complete control of conditions of air movement than has previously been obtained.

Preliminary experiments were carried out, using a fan in the manner described by Giddings. The plants under observation were placed in the direct line of the air-current from the fan blades, but, as was to be expected, the results were unsatisfactory for the reason mentioned by Giddings. The experiments were carried out in a greenhouse, but the influence of chance air-currents from doors and ventilators was still considerable unless the fan was made to rotate at a speed so high that it tended to produce rapid transpiration and premature wilting.

An index to the variations of the rate of air movement was obtained by periodical measurements of the rate of evaporation from a paper or porous-cup atmometer under constant conditions of temperature and humidity.

To obtain the steady movement of air which was desired, a special 'air-flue' was constructed, by means of which the plant could be protected from chance air-currents, and at the same time could be subjected to a current of constant velocity, the velocity being variable at will. The apparatus (see figure) consists of a wooden box 2.25 metres long and $60 \mathrm{~cm}$. in height and breadth. In one end, $A$, is a circular aperture to accommodate the revolving blades of a fan. The other end, $\mathrm{B}$, of the flue is open, and the four walls are extended by means of bent metal sheets to form a bell mouth, so as to reduce to a minimum the formation of eddy currents at the edges of the opening and the consequent irregularities in the air movement through the flue. Near the centre of the flue a section of the roof and sides is replaced by sheets of plate-glass; it is in this section $(C, D)$, which is $60 \mathrm{~cm}$. long, that the plants under observation are placed. The glass sheet at the top is divided in two, parallel to the long axis of the flue, and the two parts slide in and out in grooves. The front sheet also slides up to facilitate the manipulation of the apparatus or plant inside. This sheet is provided with a small sliding door, $\mathrm{E}, \mathrm{I} 8 \mathrm{~cm}$. square, which is convenient for minor operations not requiring the removal of the whole sheet. The woodwork is painted white so that the light may not be unduly reduced. Air is drawn through the flue from B to A by an electrically driven fan working in the aperture at A. Several fans and motors have been tried, but during long-period experiments it was found

1 Giddings, L. A.: Transpiration of Silphium laciniatum. Plant World, xvii, 1914, p. 309. 
that the ordinary fan motor is not sufficiently constant in speed but tends to slow down slightly. The most satisfactory motor was found to be one with a governing mechanism attached made by $R$. W. Paul of New Southgate. ${ }^{1}$ With this arrangement the slow air-currents, as low as 5 metres per minute, which have been mostly used, are easily obtainable.

The speed of the air-current is estimated by means of an anemometer except in the case of very low speeds, when the rate of movement of smoke through the flue is timed by a stop-watch.

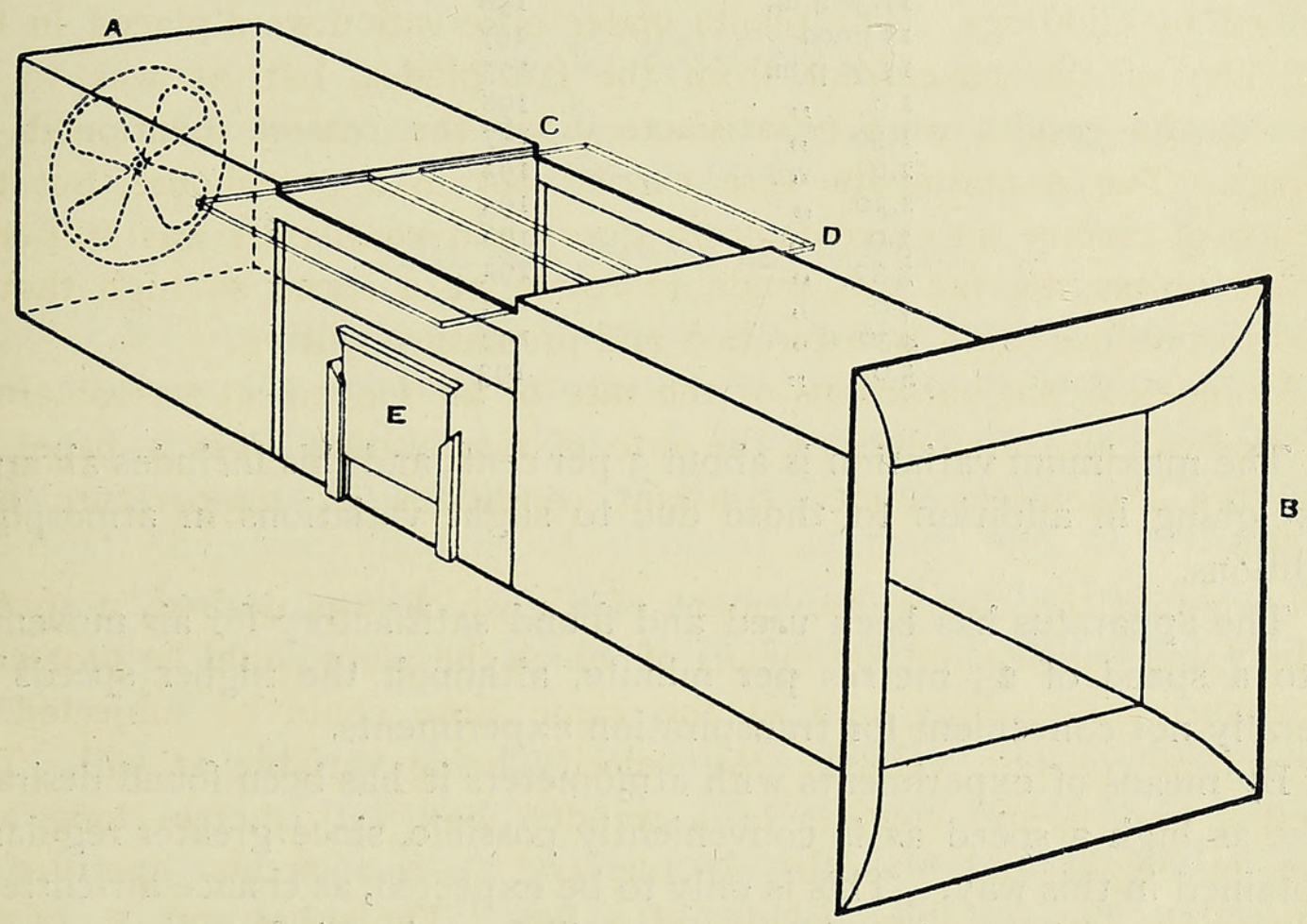

Semi-diagrammatic view of the air-flue.

The regularity of the air movement in the apparatus was tested by atmometer readings under constant conditions of temperature and humidity. An experiment carried out in a dark room will serve to show the variation which occurred. The dark room is provided with the usual double doors, which are found useful when it is necessary to keep the humidity or temperature of the room above or below that of the laboratory out of which it opens. The table on p. 220 gives an example of the variations in evaporation rate in the dark room as determined by half-hourly weighings of a porous-cup atmometer exposed in the air-flue to a wind velocity of 7 metres per minute. Periodical readings of temperature and humidity were not made,

1 When the motor reaches a certain speed, centrifugal action causes a weight attached to the shaft to move a lever which breaks the circuit through the coils. The lever works against a spring which, when the speed of the motor decreases, pulls the lever back to complete the circuit again. Thus with a continuous make-and-break mechanism, a regular speed is maintained. This type of motor was designed to drive the clock of a recording drum. 
but from the records of a thermograph and hygrograph the variations were :

Temperature, $65^{\circ} \mathrm{F}$. to $65.5^{\circ} \mathrm{F}$.

Relative humidity, $70 \%$ to $70.5 \%$.

\section{TABLE.}

\begin{tabular}{|c|c|}
\hline \multicolumn{2}{|c|}{$\begin{array}{c}\text { 30-minute per } \\
\text { ending }\end{array}$} \\
\hline \multicolumn{2}{|c|}{$\begin{array}{l}11.30 \text { a.m. } \\
12 \text { noon }\end{array}$} \\
\hline \multicolumn{2}{|c|}{$12.3^{\circ}$ p.m. } \\
\hline 1.0 & 9 \\
\hline 1.30 & 9 \\
\hline 2.0 & " \\
\hline 2.30 & "I \\
\hline 3.0 & 90 \\
\hline $3 \cdot 3^{\circ}$ & "9 \\
\hline 4.0 & " \\
\hline $4 \cdot 30$ & $"$ \\
\hline $5 \cdot 0$ & ", \\
\hline
\end{tabular}

Weight of water
evaporated (in mg.).
198
197
195
198
197
192
195
196
195
193
196
193

The maximum variation is about 3 per cent., and this includes all errors of weighing in addition to those due to slight variations in atmospheric conditions.

The apparatus has been used and found satisfactory for air movement up to a speed of 25 metres per minute, although the higher speeds are generally not convenient for transpiration experiments.

By means of experiments with atmometers it has been found desirable to use as high a speed as is conveniently possible, since greater regularity is obtained in this way. This is only to be expected, as chance air-currents, which are unavoidable in a laboratory, will have less influence on a rapid air-stream than on a slower one. 


\section{$2 \mathrm{BHL}$ Biodiversity Heritage Library}

Blackman, Vernon H. and Knight, R. C. 1917. "A method of controlling the rate of air movement in transpiration experiments." Annals of botany 31, 217-220. https://doi.org/10.1093/oxfordjournals.aob.a089641.

View This Item Online: https://www.biodiversitylibrary.org/item/232813

DOI: https://doi.org/10.1093/oxfordjournals.aob.a089641

Permalink: https://www.biodiversitylibrary.org/partpdf/320184

\section{Holding Institution}

Smithsonian Libraries

\section{Sponsored by}

Biodiversity Heritage Library

\section{Copyright \& Reuse}

Copyright Status: Not in copyright. The BHL knows of no copyright restrictions on this item.

This document was created from content at the Biodiversity Heritage Library, the world's largest open access digital library for biodiversity literature and archives. Visit BHL at https://www.biodiversitylibrary.org. 